\title{
Epidemiology of Botrytis cinerea in Sweet Basil and Implications for Disease Management
}

\author{
G. Sharabani, D. Shtienberg, and Y. Elad, Department of Plant Pathology, ARO, The Volcani Center, Bet Dagan \\ 50250; and A. Dinoor, Department of Plant Pathology and Microbiology, Faculty of Agricultural, Food and Envi- \\ ronmental Quality Sciences, The Hebrew University of Jerusalem, Rehovot 76100, Israel
}

\begin{abstract}
Sharabani, G., Shtienberg, D., Elad, Y., and Dinoor, A. 1999. Epidemiology of Botrytis cinerea in sweet basil and implications for disease management. Plant Dis. 83:554-560.

Sweet basil (Ocimum basilicum) is a herbaceous annual plant that is highly susceptible to gray mold, caused by Botrytis cinerea. Infections are initiated on the surface of stem wounds that are caused during harvest; the pathogen then progresses on the stem, killing leaves and secondary buds. When the infection reaches the main stem, the entire plant dies. A study of the epidemiology of the disease and of host-pathogen interactions led to the development of rules for effective disease management. The research was conducted in three steps. (i) Natural epidemics in commercial crops were monitored during the 1993 to 1994 and 1994 to 1995 growing seasons. Disease outbreaks were found to coincide with harvests during rainy days, whereas disease intensity did not change much when harvests were completed during rainless days. (ii) Studies under controlled environmental conditions revealed that cut ends of stems were highly susceptible soon after harvest, susceptibility diminished gradually, and stem cuts inoculated $48 \mathrm{~h}$ after harvest were rarely diseased. Observations under a scanning electron microscope showed that an opaque layer had appeared over the cut surface and, as the entire wound surface became covered, penetration of the fungus into the tissue was prevented. Based on these findings, it was hypothesized that avoidance of harvesting during rain events and application of one fungicidal spray, soon after harvest, would result in adequate disease suppression. (iii) These hypotheses were tested and corroborated in greenhouses in two experiments, in 1994 to 1995 and 1995 to 1996. Management of basil crops according to these concepts would also lower the risks for contamination of the marketable product with pesticide residues.
\end{abstract}

Additional keywords: chemical control, cultural control, environmental factors, IPM

Sweet basil (Ocimum basilicum L.) is a herbaceous annual plant of the Labiaceae family, used as a spice in the food industry and for medicinal purposes $(2,18)$. The cultivated area of sweet basil in Mediterranean countries has expanded markedly in recent years due to increasing demand on the European market. Approximately 80 ha of the herb are grown annually in Italy, 30 ha in France, and 20 ha in Israel (9). Sweet basil is grown in Israel year-round in heated greenhouses and walk-in tunnels. Seedlings are usually planted in October in

\section{Corresponding author: D. Shtienberg}

E-mail: danish@netvision.net.il

This research was supported in part by the Vegetable Production and Marketing Board; by the Chief Scientist of the Israel Ministry of Agriculture; and by the Nava Eshed Fund, Faculty of Agricultural, Food and Environmental Quality Sciences, the Hebrew University of Jerusalem, Rehovot, Israel.

Contribution from the Agricultural Research Organization, The Volcani Center, Bet Dagan 50250, Israel, No. 2288-E, 1997 series.

Accepted for publication 3 March 1999.

Publication no. D-1999-0419-02R

(C) 1999 The American Phytopathological Society containerized media or directly in soil. When plants are 40 to $60 \mathrm{~cm}$ in height (usually within 1 to 2 months after planting), the upper part of the canopy is harvested manually using sharp knives. Offshoots (approximately 20 to $25 \mathrm{~cm}$ long) bearing two or three leaf clusters each are packed (in 1-kg packages) and delivered for shipment. Harvesting breaks the apical dominance and lateral buds start to grow and develop offshoots that will be harvested subsequently. A crop is harvested typically every 3 to 5 weeks, the frequency depending mainly on temperature and solar irradiation.

The types of basil grown in Israel are local selections from imported European and American cultivars. All are highly susceptible to gray mold, caused by Botrytis cinerea Pers.:Fr. Observation of gray mold epidemics in commercial greenhouses showed that infection initiates on the surface of stem wounds that are made during harvesting. The pathogen then progresses on the stem, killing leaves and secondary buds; when it reaches the main stem, the entire plant dies. Healthy leaves touching diseased tissues of adjacent plants may also become infected. After infection, the pathogen progresses along the leaf blade and petiole until it reaches the stem, where it continues to progress upward and downward. Leaves and stems infected with the pathogen produce abundant mycelium covered with conidia that are readily disseminated and support the build-up of the epidemic. Under conditions favorable for gray mold development (temperatures in the range of 9 to $21^{\circ} \mathrm{C}$ and prolonged periods of high relative humidity; $6,12,13,20$ ), the disease may cause complete destruction of a crop. B. cinerea also develops postharvest. One infected leaf may rot an entire $1-\mathrm{kg}$ package during storage, shipment, and marketing (N. Aharoni, personal communication). Consequently, strict quality control is practiced during product processing and marketing.

The nature of gray mold (pre- and postharvest disease) and its destructive potential motivates growers to make every effort possible for its prevention, including various control measures. To eradicate overseasoning inoculum of $B$. cinerea (and also of Fusarium oxysporum f. sp. basilici, the causal agent of Fusarium wilt and crown rot), growers disinfect soil or growth medium with methyl bromide prior to planting. In some cases, space structure solarization is practiced (8). Heating and forced ventilation, and opening of the greenhouse side vents (weather permitting), are used to dry the foliage and minimize the duration of leaf wetness. Sanitation (removing of infected plants or plant organs) is also practiced. However, these measures do not always provide adequate disease suppression and fungicides are applied to the foliage as well. Since there is a lack of knowledge concerning the optimal timing for spraying, sprays are applied frequently, up to 5 to 10 times during a growing season. Disease management is effective in most cases, but it is not uncommon for severe gray mold epidemics to develop even in intensively managed crops.

Since sweet basil is an herb crop and the marketable product includes fresh leaves and stems, tolerance thresholds for residues in the foliage are low or zero. Samples are taken routinely from shipments before export. If pesticide residues are above the permitted threshold, the entire shipment is destroyed and the producer of that shipment is not eligible to export product for another 30 days. The current situation has put the growers in a difficult situation. On one hand, for production of a marketable, high-quality product, they 
must eliminate $B$. cinerea from the crop (and the best available means is application of foliar fungicides). On the other hand, poor use of that measure may result in rejection of the entire shipment, with consequential financial loss. This situation prompted research aimed at the development of means to suppress gray mold adequately with minimal fungicide use. Although much is known about $B$. cinerea, and gray mold epidemics have been studied thoroughly in many crops, research on $B$. cinerea in sweet basil has not been published. The lack of knowledge hinders the development of rational guidelines for disease management. A detailed study on the epidemiology of the disease and of host-pathogen interactions could lead to the development of concepts for effective disease suppression, the objective of the present work. A preliminary report was published elsewhere (17).

\section{MATERIALS AND METHODS}

Research was performed in three phases. First, natural epidemics in commercial crops were monitored and analyzed to identify key elements in host-pathogen interactions. Second, trials were done in controlled environments to examine these interactions and to form the basis for concepts for effective disease suppression. Third, the developed concepts were evaluated in an experimental greenhouse.

Natural epidemics in a commercial greenhouse. Experiments were conducted in a polyethylene-covered commercial walk-in tunnel during the growing seasons of 1993 to 1994 and 1994 to 1995. The tunnel was located in the inner coastal plains of Israel; its size was 9 by 45 by 3.5 $\mathrm{m}$ (width by length by height). Sweet basil plants of the local selection (called the "Swiss cultivar") were planted on raised beds in growth medium in October of each year. Beds were $1 \mathrm{~m}$ wide and the distance between beds was $80 \mathrm{~cm}$. Each bed consisted of four rows of plants, $20 \mathrm{~cm}$ apart; plants were spaced $15 \mathrm{~cm}$ apart within rows. The crop was drip-irrigated and the tunnel heated to $19^{\circ} \mathrm{C}$ with hot water pipes placed aboveground. The side vents of the tunnel were opened daily (0900 to $1600 \mathrm{~h}$ ) on rainless days but were closed on rainy days. The crop was maintained and cultivated according to the recommendations given to commercial basil growers in the region.

Experiments were conducted during the seasons of 1993 to 1994 and 1994 to 1995. Eight experimental plots were designated in the central beds of the tunnel; each plot was $6 \mathrm{~m}$ long and one bed wide. Plots were divided into two treatments in a randomized block design. In one treatment, plants were not sprayed with fungicides against $B$. cinerea (untreated control) and in the other treatment, fungicides were applied according to the recommended spraying schedule (every 5 to 7 days). Sprays were applied with a backpack sprayer adjusted to $275 \mathrm{kPa}$. Spray volume was calibrated to 1,000 to 1,500 liters/ha. The fungicides used were those registered at that time for $B$. cinerea in sweet basil: iprodione $(0.5 \mathrm{~g}$ a.i./liter of Rovral 50 WP, Rhone-Poulenc, Lyon, France); chlorothalonil (1.75 g a.i./liter of Bravo 50 SC, ISK BioScience, Plainsville, $\mathrm{OH})$, and fenbuconazole $(0.1 \mathrm{~g}$ a.i./liter of Indar 5 EC, Rohm and Haas
Co., Philadelphia). Seven sprays were applied in the 1993 to 1994 experiment and six in the 1994 to 1995 experiment (Fig. 1).

Natural epidemics developed in both seasons. First disease symptoms were observed in December of each year. Disease intensity was assessed at 7- to 20-day intervals as follows. A total of 20 plants were randomly chosen in the inner rows of each experimental plot (at a distance of at least $1 \mathrm{~m}$ from the edge of the plot). Each plant was examined, and infected stem cuttings were counted and averaged by plot. Crops were harvested three times in each experiment. Harvesting was carried out by farm workers who cut the upper portion of the canopy $(25$ to $30 \mathrm{~cm})$ with sharp knives. The timing of harvesting was determined by the grower according to the condition of the crop (Fig. 1) and in response to specific orders issued by Agrexco (the agricultural Export Company, Tel-Aviv, Israel).

Microclimatic variables (air and leaf temperature, relative humidity in the air and within the crop) were measured routinely. In this article, data for relative humidity within the crop are presented. Relative humidity in the greenhouse was measured with a PCRC-11 electro-humidity sensor and recorded hourly by means of C21X data loggers (Campbell Scientific, Inc., Logan, UT). Relative humidity sensors were placed inside the canopy, with shields facing south to protect the sensors from intense radiation. Rain records were obtained from a standard meteorological station of the Israeli Meteorological Service located $4.6 \mathrm{~km}$ from the experimental site.
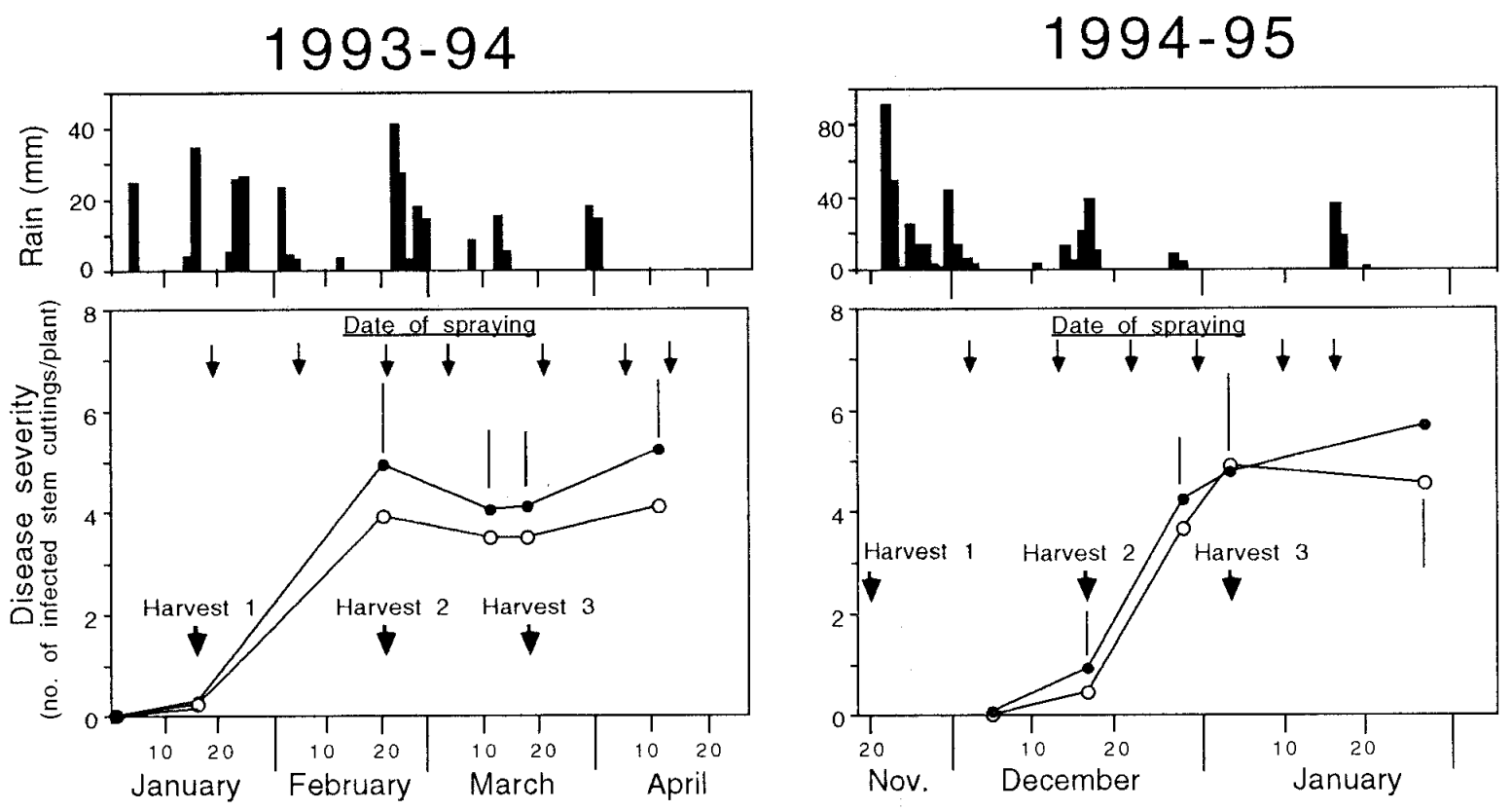

Fig. 1. Botrytis cinerea progress curves in sweet basil grown in commercial walk-in tunnels in two growing seasons. Plots were left untreated (full symbols) or sprayed with fungicides (open symbols) at the times indicated by arrows. Three harvests were performed each year and arrows indicate their times. Bars indicate the least significant difference (at $P \leq 0.05$ ) for each disease sampling date as determined by Fisher's protected least significant difference test. Quantity and timing of rain events for each season are shown in the upper graphs. 
Whole plant experiments under controlled environment conditions. Sweet basil seeds (Swiss cultivar) were sown in boxes filled with $2: 1$ peat-perlite mixture. Boxes were placed in a greenhouse maintained at 15 to $25^{\circ} \mathrm{C}$ during night and day, respectively, until plants had two true leaves. At that point, they were transplanted into 1-liter pots, six plants per pot. When plants were $20 \mathrm{~cm}$ in height, they were transplanted to 3-liter pots. The upper section of the canopy was cut twice to induce development of side shoots. Plants were irrigated every 1 to 3 days and fertilized every 4 to 7 days with a solution containing 20-10-10 N-P-K. Unless stated otherwise, fungicides were not applied to the plants.

When the plants were 7 weeks old, they were inoculated with $B$. cinerea conidia. All shoots were cut with a knife $1 \mathrm{~cm}$ above a leaf cluster and inoculum was applied to the surface of wound. The isolate of the pathogen used was obtained originally from naturally infected rose flower (4). It was maintained and grown on potato dextrose agar (PDA, Difco Laboratories, Detroit). This isolate sporulates abundantly in the dark and is capable of infecting various plant hosts, including basil. Suspensions of conidia $\left(5 \times 10^{5} / \mathrm{ml}\right)$ were prepared from 12- to 14-day-old cultures grown at $20^{\circ} \mathrm{C}$ in the dark. Sporulating cultures were agitated in sterile distilled water and filtered through folded muslin. Conidia concentration was determined with a haemocytometer and adjusted as necessary. Droplets of conidial suspension $(5 \mu \mathrm{l}$ containing 2,500 conidia) were placed on the surface of stem cuts. Controls were treated with distilled water. After inoculation, plants were covered with clear polyethylene bags (to maintain high humidity) and placed in a growth chamber at $20 \pm 2^{\circ} \mathrm{C}$ for 14 to 21 days. By that time, infected stems developed typical rot, which usually was accompanied by production of abundant masses of conidia.

Plants in pots were used to evaluate the effects of wound age on the incidence of infection and on the efficacy of a fungicide applied directly to the wound. In experiments on wound age, plants were cut at various times prior to inoculation. Cutting was performed $60,48,24,16,6,3$, and 0.5 $\mathrm{h}$ before inoculation. During the time that passed between cuttings and inoculation, the plants were maintained in the greenhouse. In experiments on chemical control, plants were harvested and the fungicide pyrimethanil ( $0.75 \mathrm{~g}$ a.i./liter of Mythos 30 SL, AgrEvo, Berlin) was applied using a paintbrush to individual stem wounds. Treatments included various concentrations of the fungicide $(0,0.25,0.5,0.75$, and $1.0 \%$ product) and timing of application after harvest ( 2 and $48 \mathrm{~h}$ ). Infected stems per pot and total number of stems per pot were counted and used to calculate disease incidence (proportion of infected stems). Experiments in pots included six replicates (pots) per treatment. Treatments were arranged in a completely randomized design. Experiments on wound age were repeated twice and experiments on chemical control were repeated once.

Experiments with stem pieces. Effect of wound age on infection was evaluated also by means of a stem-piece bioassay. This bioassay was a modified version of the method used with tomato stem pieces in earlier studies (16). Basil stems 20 to 30 $\mathrm{cm}$ long were harvested from the commercial or the experimental greenhouses or

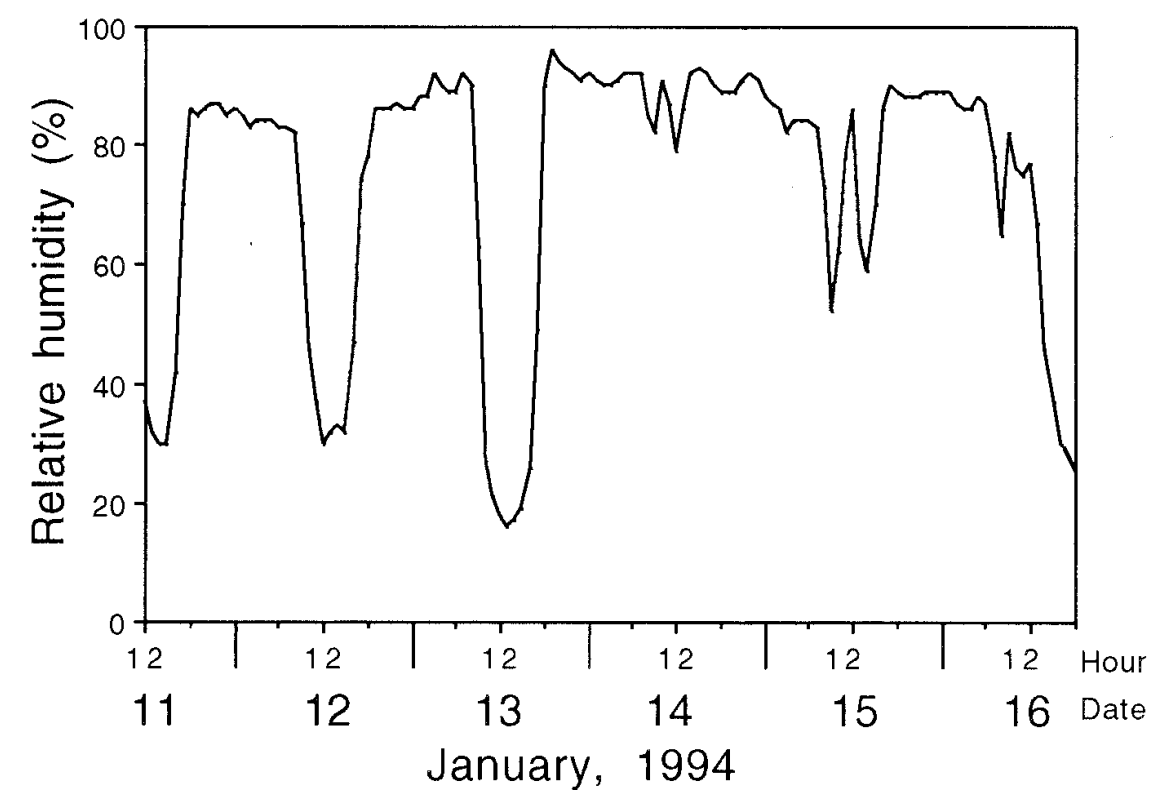

Fig. 2. Changes in relative humidity (\%) recorded within a commercial sweet basil crop in the 1993 to 1994 experiment $(12=$ noon). On 14 January there was $4 \mathrm{~mm}$ of rain and on 15 January there was $34 \mathrm{~mm}$ of rain. from potted plants (source plants were not treated with fungicides). The top $5 \mathrm{~cm}$ of the stems was discarded and the nonwoody remaining section was cut with a sharp knife into pieces 4 to $5 \mathrm{~cm}$ in length. Six pieces were inserted vertically into a 10-cm-diameter pot containing autoclaved perlite previously wetted with distilled water. The surface of the wound was inoculated with $5 \mu$ l of conidial suspension (2,500 conidia/droplet). Control stempieces were treated with distilled water. Pots containing perlite with inoculated stem pieces and controls were placed in plastic boxes ( 38 by 33 by $16 \mathrm{~cm}$ ) and these were enclosed in a transparent polyethylene bag and placed in an illuminated (Photosynthesis active radiation [PAR] = $75 \mu \mathrm{mol} / \mathrm{m}^{2} / \mathrm{s}$ at table level) walk-in growth chamber with fan ventilation, maintained at $20 \pm 1.5^{\circ} \mathrm{C}$. In experiments on wound age, pots with stem pieces were prepared at various time periods before inoculation; boxes were then covered with polyethylene bags until inoculation. Stem pieces were prepared $48,24,6$, and $1 \mathrm{~h}$ before inoculation. After inoculation, stem pieces were assessed every 1 to 3 days for severity of infection. Disease severity (proportion of rotted section of the stem piece) was assessed visually for each stem piece individually and averaged by pot. Experiments included four replicates (pots with six stem pieces each) per treatment, and were arranged in a randomized block (boxes with pots) design. Stem piece experiments were done four times.

Scanning electron microscopy. A scanning electron microscope (SEM) was used to observe the events occurring at the wound surface at various times after harvest. Plants were grown in pots as described above and stems were cut 5 days, $24 \mathrm{~h}$, and $6 \mathrm{~h}$ before preparation of the microscopic slides. Half of the stem cuts were inoculated with $B$. cinerea conidia as indicated above and incubated in a humidity chamber. The other half was not inoculated. A thin layer (transverse) of the cut wound surface was prepared for SEM observation. Fixation of the section was done in a hermetically closed vessel with vapor of $3.5 \%$ glutaraldehyde (Sigma Chemical Co., St. Louis). Specimens were allowed to dry in air, coated with gold palladium in a Polaron E-500 sputter coater (Polaron Equipment Ltd., Watford, UK), and viewed under a SEM (Jeol JSM T 330A) under magnification of $35 \times$ to $5,000 \times$.

Trials in an experimental greenhouse. The intensity of gray mold in plots harvested during rainy or on rainless days and the efficacy of fungicide applied soon after harvest were evaluated in trials conducted in an experimental greenhouse in 1994 to 1995 and 1995 to 1996 . Sweet basil plants (Swiss cultivar) were planted in a peatcompost mixture placed in boxes (150 by 80 by $35 \mathrm{~cm}$ ) in a polyethylene-covered experimental greenhouse. Pipes of hot 
water $\left(18^{\circ} \mathrm{C}\right)$ were installed on the growth medium. Vents were used to force air into the greenhouse in order to obtain microclimatic uniformity. Eight boxes laid end to end formed a 12-m-long bed. There were three beds spaced $50 \mathrm{~cm}$ apart. Plants were planted in early October of both years. Each bed consisted of three rows of plants, $15 \mathrm{~cm}$ apart, with $15-\mathrm{cm}$ intra-row spacing. Plants were raised and maintained according to the cultural practices recommended for sweet basil production. The experimental design was a completely randomized design with four replicates. Each plot was $1.5 \mathrm{~m}$ long and one bed wide, with 30 plants. Plants were not inoculated artificially, but $B$. cinerea inoculum was introduced into the greenhouse prior to harvesting. In the 1994 to 1995 experiments, infected potted basil plants were placed between the rows. In the 1995 to 1996 experiments, open petri plates with 10-dayold cultures were placed between the rows. Fans installed in the greenhouse produced wind that assisted in the spread of B. cine$r e a$ conidia from these sources to the crop.

Treatments included various timing of harvests and fungicide treatments. The 1994 to 1995 experiment consisted of six treatments in a factorial design. The first factor was harvesting time: 2 days, 1 day, or $30 \mathrm{~min}$ before wetting the foliage. A mist sprinkler system was installed inside the greenhouse at a height of $2 \mathrm{~m}$ above plants. The mist sprinklers were activated for $15 \mathrm{~min}$, which completely wetted the crop. This was done to simulate wetting of the foliage during rain events. The second factor was fungicide treatment: either an untreated control or fungicide-treated. Pyrimethanil (at a concentration of $0.25 \%$ ) was applied to runoff 1 to $2 \mathrm{~h}$ after harvest by means of a forced-air sprayer. To minimize drift, adjacent plots were protected by a wooden barrier during spraying.

The 1995 to 1996 experiment also included six treatments, but only three will be reported here. In the other three treatments, the efficacy of the detergent LQ215 (Zohar Dalia, Israel) against $B$. cinerea was examined. Treatments consisted of: (i) harvesting during a rainy day; (ii) harvesting during a rainless day (4 to 5 days after harvesting treatment number [i]); and (iii) harvesting during a rainless day (on the same days as treatment number [ii]) plus application of a fungicide (pyrimethanil $0.25 \%) 1$ to $2 \mathrm{~h}$ after harvest. Harvesting during rainy days was planned for occasions when the weather forecast was for substantial rainfall $(>10 \mathrm{~mm})$. There were three harvests: one was carried out on 11 and 16 December 1995 (rainy and rainless day, respectively); the next on 23 and 28 January 1996 (rainy and rainless day, respectively); and the final one on 26 February 1996 (rainy day). Only two treatments were included in the third harvest: untreated control and harvesting plus immediate application of a fungicide. Prior to each harvest, the stems to be cut were marked with small colored plastic bands. Different colored bands were used for each harvest, so that it was possible to identify easily when each stem had been harvested. Diseased and healthy stems per plant were counted and disease incidence determined 2 to 3 weeks after each harvest. Only those stems that were harvested at the preceding harvest were recorded. Treatments were compared statistically using Fisher's protected least significant difference (LSD) test at $P \leq 0.05$. Control efficacy (CE, \%) of the treatments was calculated using disease incidence records in the untreated control $\left(D_{\mathrm{u}}\right)$ and in the treated $\left(D_{\mathrm{t}}\right)$ plots as
$\mathrm{CE}=100-\left(D_{\mathrm{t}} / D_{\mathrm{u}}\right) \times 100$. Harvested clusters were tested for residues of pyrimethanil by the national official laboratory, the Pesticide Residues Section of the Plant Protection and Inspection Services, Israeli Ministry of Agriculture (Bet Dagan, Israel). The pyrimethanil residues were determined by gas chromatography with a nitrogen phosphor detector (NPD) with $0.05-p p m$ (per dry weight of plant tissue) accuracy.

\section{RESULTS}

Natural epidemics in a commercial greenhouse. During the two growing seasons, the pattern of disease progress in
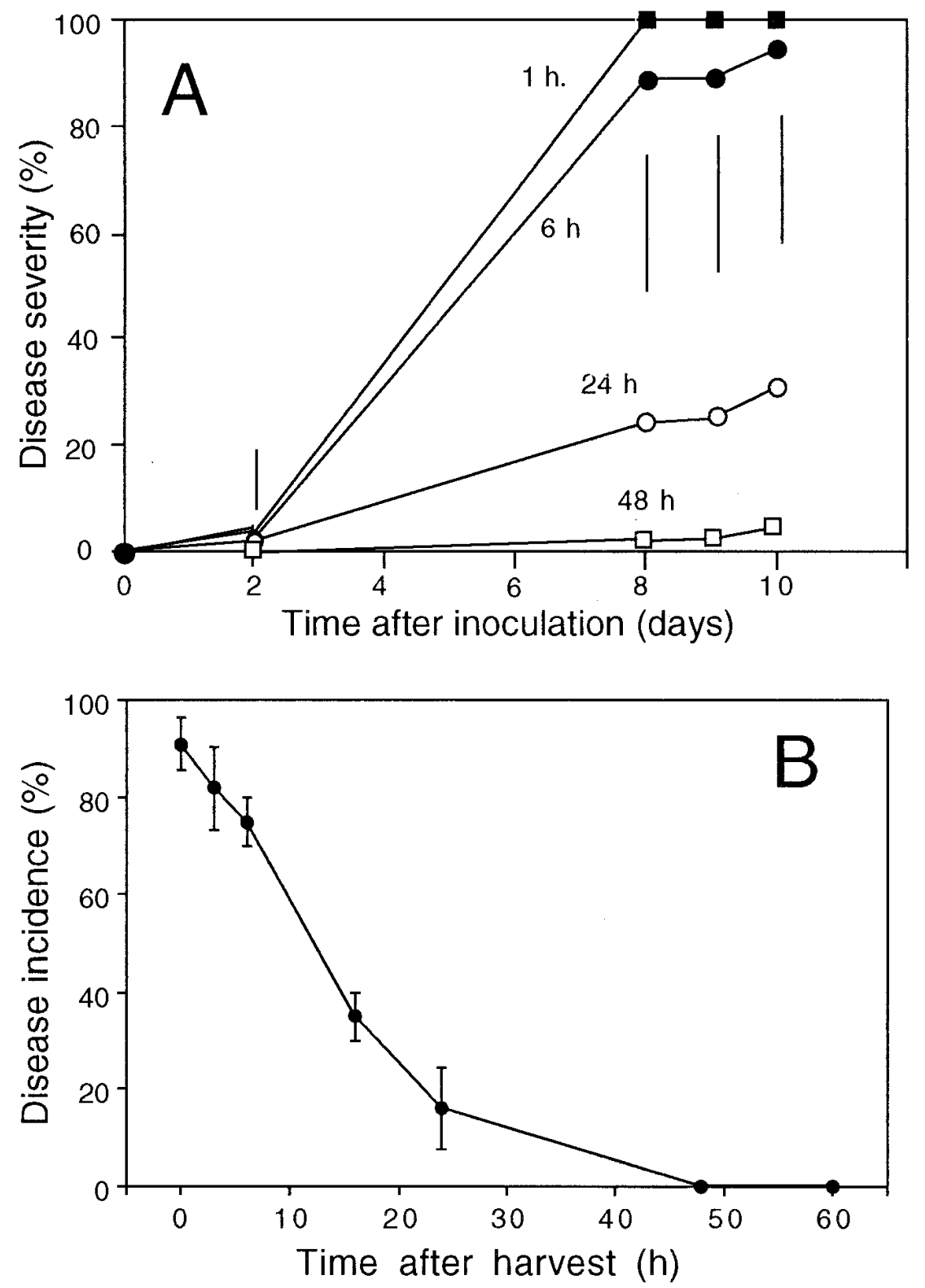

Fig. 3. Susceptibility of sweet basil stem wounds to infection by Botrytis cinerea. Experiments were carried out with (A) stem pieces or (B) with potted plants. Stem cuts were inoculated at various times $(0$ to $60 \mathrm{~h})$ after harvest. For the stem piece experiment, disease severity was recorded at various times after inoculation. Bars indicate the least significant difference (at $P \leq 0.05$ ) for each sampling date as determined by Fisher's protected least significant difference test. For the potted plant experiment, disease incidence was assessed once, 21 days after inoculation. Bars indicate the standard error. 
untreated plots followed similar trends. Disease onset was at the beginning of the rainy season, but gray mold incidence remained relatively low at first. Disease incidence increased between mid-January and February in the 1993 to 1994 experiment and between mid- and late December in the 1994 to 1995 experiment. Disease incidence did not increase much thereafter. In both years, the occurrence of disease outbreaks coincided with a harvest that was carried out during a rainy day. In the first experiment, this harvest was done on 15 January 1994 and, in the second experiment, on 18 December 1995. Other harvests were done a few days before or after the occurrence of rain events and were not associated with disease outbreak (Fig. 1). During rains, the side vents of the walk-in tunnel were not opened and relative humidity within the tunnel did not follow the common diurnal high-low pat- tern; instead, relative humidity was continuously high for many hours (Fig. 2).

Experiments in commercial tunnels included plots that were sprayed with fungicides. Although seven sprays were applied in the 1993 to 1994 experiment and six sprays in the 1994 to 1995 experiment, disease incidence in the fungicide-treated plots did not differ significantly $(P \leq 0.05)$ from that recorded in the untreated plots. In both years, fungicides were not applied
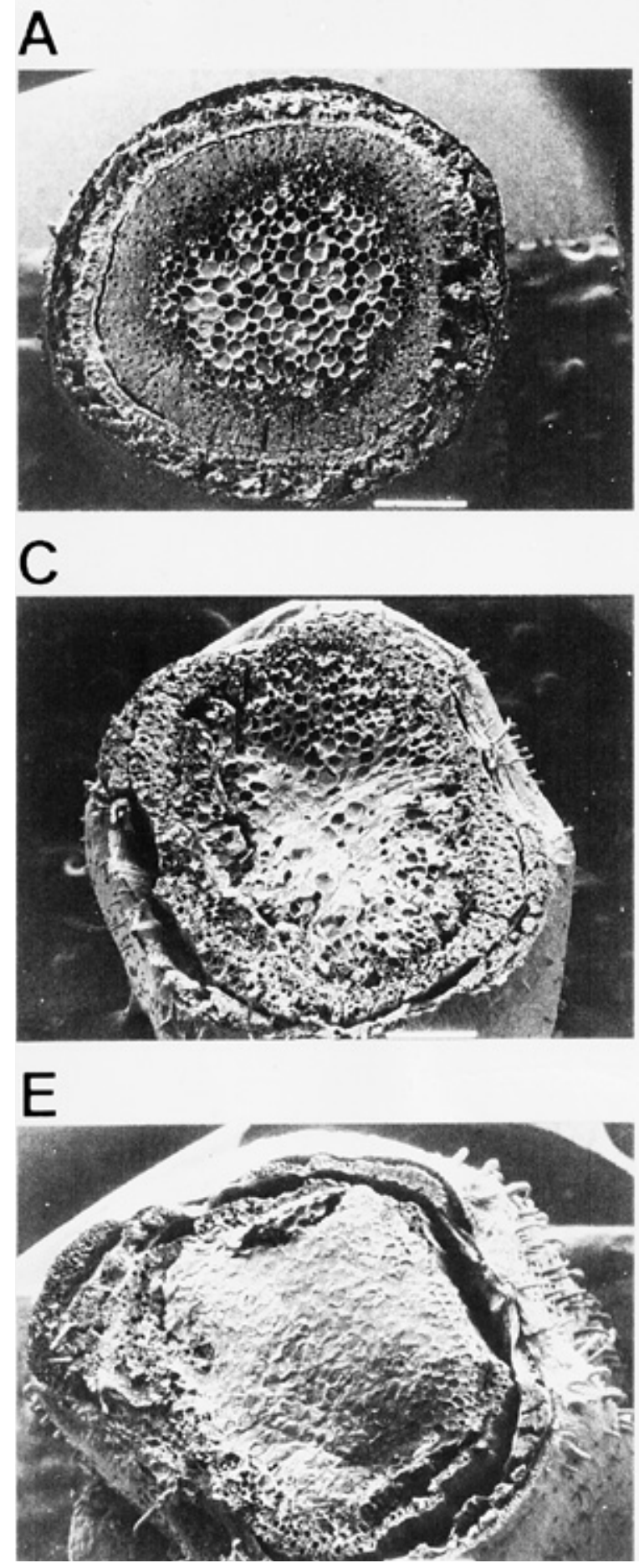

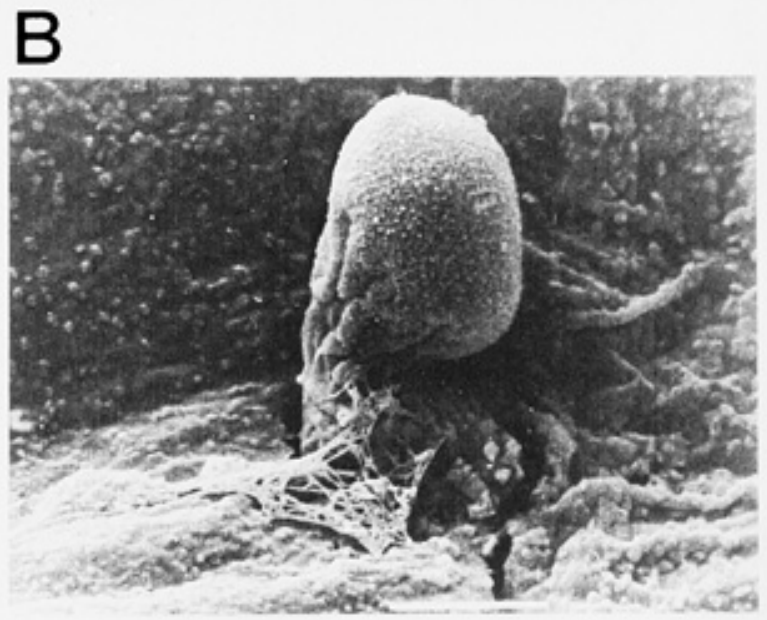

D
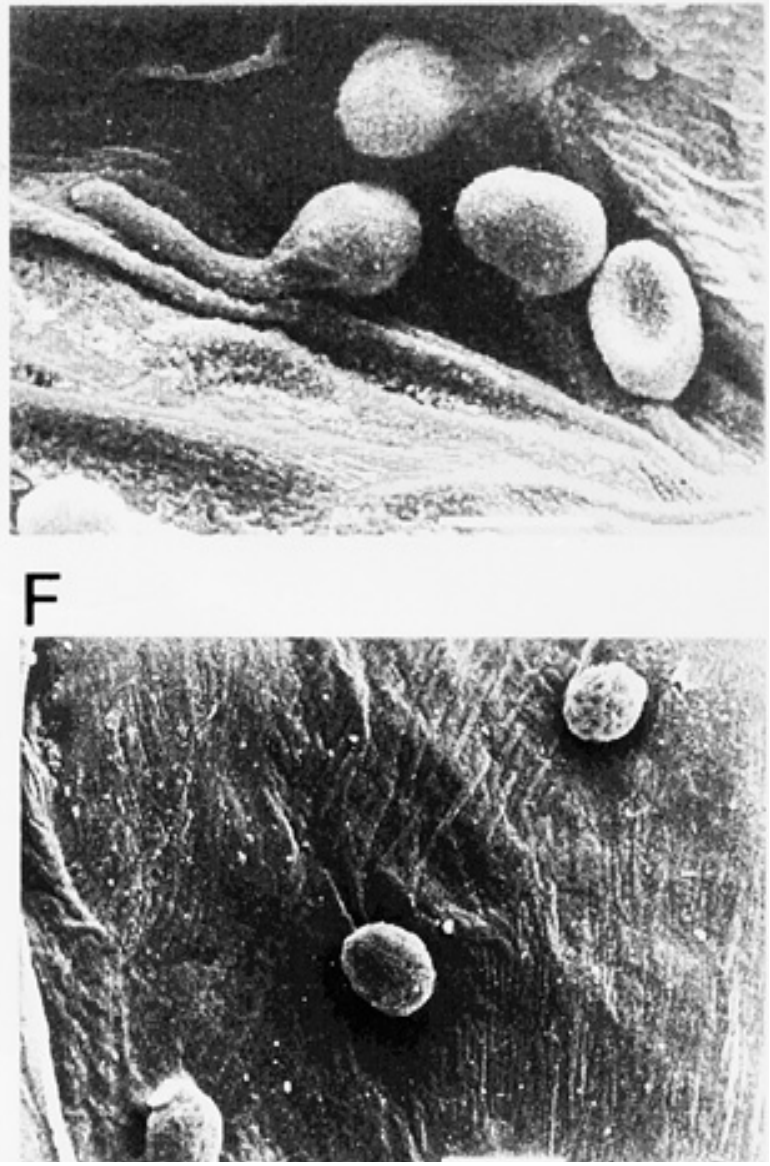

Fig. 4. Observations made under scanning electron microscope of the events that occur at the wound surface of sweet basil, at various times after harvesting and inoculation with Botrytis cinerea. Micrographs were taken (A and B) $6 \mathrm{~h},(\mathbf{C}$ and D) $24 \mathrm{~h}$, or (E and F) 5 days after harvest. The stem cuts were not inoculated (A, C, and E) or inoculated with B. cinerea conidia (B, D, and F) and incubated in high humidity for $6 \mathrm{~h}$ to allow germination and penetration of host tissue. Bars indicate the scale; $\mathrm{B}, \mathrm{D}$, and $\mathrm{F}=5 \mu \mathrm{m}, \mathrm{A}, \mathrm{C}$, and $\mathrm{E}=500 \mu \mathrm{m}$. 
within $24 \mathrm{~h}$ after the harvest that apparently was associated with the disease outbreak (Fig. 1).

Experiments under controlled environment conditions. Experiments conducted with stem pieces and potted plants resulted in similar findings. Stem wounds were highly susceptible soon after harvest and 90 to $100 \%$ of the stem pieces or stem cuts became diseased. Susceptibility diminished gradually as time from harvest to inoculation increased. When the elapsed time difference was 24 h, 20 to $30 \%$ of the stem pieces or stem cuts were diseased; when it was $48 \mathrm{~h}$ or more, fewer than $5 \%$ of the stem pieces or stem cuts were diseased (Fig. 3). An attempt to isolate $B$. cinerea from symptomless stem cuts made 14 days after inoculation revealed that the conidia on the wound remained viable.

In a set of experiments conducted in pots, basil plants were harvested and immediately inoculated with $B$. cinerea conidia. After $2 \mathrm{~h}$, the stem cuts were treated with pyrimethanil. This reduced disease incidence significantly $(P \leq 0.05)$ by 80 to $100 \%$ (in different experiments and concentrations of the fungicide). Application of the fungicide $48 \mathrm{~h}$ after harvest and inoculation resulted in insignificant effect $(\mathrm{CE}=0$ to $5 \%)$ on disease incidence.

SEM observations of wound surfaces. When inoculated soon after harvest, $B$. cinerea conidia germinated and penetrated the stem directly via the wounds on the cut surface (Fig. 4A and B). However, $24 \mathrm{~h}$ after harvest, an opaque layer had started to appear on the cut surface and direct penetration of the pathogen into the stem was less common (Fig. 4C and D). At 5 days after harvest, the cut area was evenly covered with that layer and conidia of $B$. cinerea did not germinate (Fig. 4E and F).

Trials in an experimental greenhouse. In the experimental greenhouse, branches were harvested at various times before and after rain events. In the 1994 to 1995 experiment, disease incidence was lower (CE $=52$ to $59 \%$ ) on plants cut 2 or 1 days before wetting the foliage than on plants cut just before wetting the foliage. Application of a fungicide at any of the harvests reduced disease significantly $(\mathrm{CE}=64$ to $69 \%$ ) as compared with disease incidence in plots harvested on the wetting day (Fig. 5). An experiment conducted in 1995 to 1996 verified these findings. Harvests that were carried out on rainy days resulted in severe infections. However, harvesting on rainless days resulted in significantly $(P \leq$ 0.05 ) lower disease incidence (52 to $62 \%$ reduction). Application of pyrimethanil soon after harvest was highly effective and reduced disease incidence significantly $(\mathrm{CE}=85$ to $90 \%)$ regardless of whether or not harvesting was performed on a rainy day (Fig. 6). Yield accumulated after the two first harvests reflected the efficacy of disease control. The average yield in plots harvested on rainy days $\left(2.4 \mathrm{~kg} / \mathrm{m}^{2}\right)$ was significantly lower than the yield in plots that were harvested on rainless days (3.4 $\mathrm{kg} / \mathrm{m}^{2}$ ). The yield in plots harvested on rainless days and sprayed immediately with pyrimethanil $\left(5.1 \mathrm{~kg} / \mathrm{m}^{2}\right)$ was significantly $(P \leq 0.05)$ greater than the two other treatments.

Samples taken from harvests number 2 and 3 were checked for pyrimethanil residues. In samples taken from harvest number 2 (the crop was sprayed 6 weeks earlier, soon after harvest number 1) pyrimethanil was recovered at a concentration of $2.25 \pm 0.52 \mathrm{ppm}$ (mean \pm standard error, calculated on a dry weight basis). Although this rate was not significantly different from the permitted $2 \mathrm{ppm}$ threshold (examined by one-tailed $t$ test at
$P=0.05)$, it is relatively high. Pyrimethanil residues $(0.45 \pm 0.05 \mathrm{ppm})$ also were detected in samples taken from untreated control plots. In samples taken from harvest number 3 (the crop had been sprayed 4 weeks earlier, soon after harvest number 2 ), pyrimethanil was recovered in the harvested material at a level $(0.22 \pm 0.06$ ppm) that was significantly lower than the permitted $2 \mathrm{ppm}$ threshold. The fungicide was not recovered at all in plant material sampled from untreated plots.

\section{DISCUSSION}

Epidemics of gray mold in sweet basil occur when susceptible host tissue is present coincidentally with a prevalence of environmental conditions that are condu-

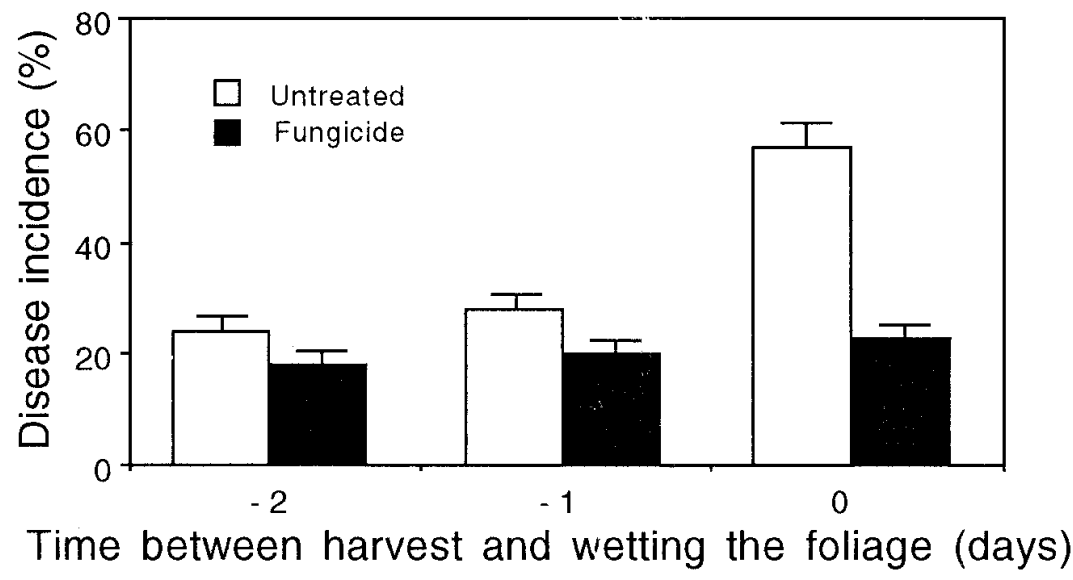

Fig. 5. Effects of harvesting time in relation to wetting of the foliage and fungicide on the incidence of gray mold (caused by Botrytis cinerea) in sweet basil. The experiment was conducted in an experimental greenhouse during the 1994 to 1995 season. Harvesting was carried out 2 days, 1 day, or $30 \mathrm{~min}$ (day 0) before wetting of the foliage. The fungicide pyrimethanil was applied (at a concentration of $0.25 \%) 1$ to $2 \mathrm{~h}$ after each harvest. Bars indicate the standard error.

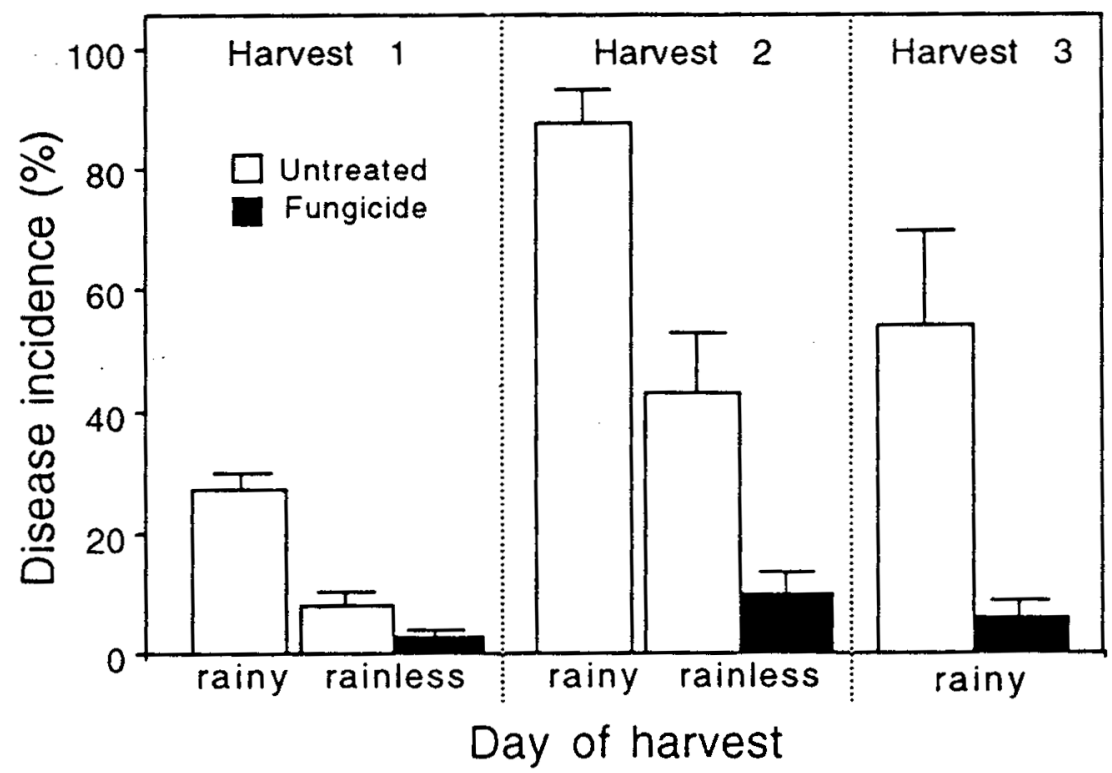

Fig. 6. Effects of rain during harvesting time and fungicide on the incidence of gray mold (caused by Botrytis cinerea) in sweet basil. The experiment was conducted an experimental greenhouse during the 1995 to 1996 season. Harvests 1 and 2 were carried out on a rainy day (>10 mm rain) or on a rainless day. Harvest 3 was carried out on a rainy day. The fungicide pyrimethanil was applied (at a concentration of $0.25 \%$ ) 1 to $2 \mathrm{~h}$ after each harvest. Bars indicate the standard error. 
cive to the pathogen. The sites of $B$. cinerea infection are wounds created on the stem cut end during harvest. Stem wounds were highly susceptible to infection soon after harvest. Susceptibility diminished gradually with time and, by $24 \mathrm{~h}$ after harvest, it was relatively low. At $48 \mathrm{~h}$ after harvest, most of the artificially inoculated stem cuts remained uninfected (Fig. 3). Thus, host tissue is susceptible for infection for a relatively short period of time. Similar phenomena were reported for $B$. cinerea in other hosts, such as tomato (16), geranium (10), and apple fruit (14), and also in other host-pathogen interactions such as Pythium ultimum in geranium (3).

Soon after harvest, the cut surface consisted of numerous wounded cells that served as the port of entry for the fungus. However, as time since harvest passed, an opaque layer was deposited gradually over the cut surface and blocked the microscopic openings. At 5 days after harvest, when the wound surface was evenly covered with that layer, conidia of $B$. cinerea did not germinate and infection did not occur (Fig. 4). A preliminary study of the characteristics of cell walls of the cut basil stem revealed the presence of lignin, suberin, and callose. However, only lignin accumulated with time in the wound tissue and the two other polymers remained at a steady level for 5 days after wounding (results not shown). These polymers are associated with increased resistance of plant tissues to pathogen infection, including $B$. cinerea $(5,14)$.

For germination and infection, conidia of $B$. cinerea require free moisture on the plant surfaces $(1,11,13,15)$. Usually, a drop of moisture is formed on the basil stem wound surface after harvest, due to the root pressure. The heating and ventilation regimes and the daily opening of side vents prevent persistence of this drop for long periods. However, during rain events, growers avoid opening the vents and the relative humidity within the greenhouse remains high for many hours (Fig. 2). Moreover, condensation of water on the inner side of the polyethylene covering drops onto the plants, adding to crop wetness. When harvests are performed on rainless days, moisture duration on the infection site is insufficient to support infection. Outbreaks of $B$. cinerea following rain events also were reported in nonheated tomato and cucumber greenhouses $(7,19)$.

The pathogen infects mainly through wounds on stems caused during harvest, and these sites become resistant to pathogen penetration within 24 to $48 \mathrm{~h}$; therefore, sprays applied later than $24 \mathrm{~h}$ after harvest are not expected to contribute much to disease control. This analysis may also assist in interpreting the results recorded in the commercial crop (Fig. 1).

In our experiments, harvesting on a rainless day resulted in a significant reduction in disease incidence $(\mathrm{CE}=52$ to $62 \%$ ), as compared with harvesting on a rainy day. Moreover, application of a fungicide once, within 1 to $2 \mathrm{~h}$ after harvest, further improved disease suppression (CE $=64$ to $90 \%$ ). In plots treated according to these guidelines, disease incidence remained low $(<10 \%)$ throughout the growing season (Figs. 5 and 6).

Application of fungicides only after harvesting is expected not only to reduce the number of sprays and improve disease control, but also to minimize the risk of pesticide residues in the marketable product. During harvest, the upper portion of the canopy is removed for processing and marketing. Soon after harvest, lateral buds start to grow and the offshoots developed thereafter form the yield to be collected in the next harvest. These new leaves and shoots had not been exposed to the spray that was applied after the preceding harvest. The currently available systemic fungicides effective against $B$. cinerea are translocated only through the xylem; therefore, fungicide residues are not likely to accumulate in leaves and stems that developed after fungicide application. Samples taken from two harvests (in the 1995 to 1996 experiment) confirmed these expectations.

The findings from this study were used to formulate new concepts for $B$. cinerea management in sweet basil, such as avoidance of harvesting during rainy days and application of fungicide once, soon after harvest. These concepts have already been implemented by commercial growers and enable them to control gray mold effectively with low risk of contaminating the marketable product with fungicide residues. It may be possible to apply these concepts also to other pathosystems where host-pathogen interactions are similar to those described here for $B$. cinerea in sweet basil.

\section{LITERATURE CITED}

1. Blakemen, J. P. 1980. Behavior of conidia on aerial plant surfaces. Pages 115-151 in: The Biology of Botrytis. J. R. Coley Smith, K. Verhoeff, and W. R. Jarvis, eds. Academic Press, London.

2. Brown, S. H., and Valenzuela, L. H. 1992. Fuji apple, radicchio, basil, walnut top specialty crop research needs. Calif. Agric. 46(4):16-18.

3. Cline, M. N., and Neely, D. 1983. The histology and histochemistry of the wound healing process in geranium cuttings. J. Am. Soc.
Hortic. Sci. 108:496-502.

4. Elad, Y. 1988. Effect of biotic conditions on development of gray mould of rose and scanning electron microscopy. Phytopathol. Mediterr. 28:122-130.

5. Elad, Y. 1997. Responses of plants to infection by Botrytis cinerea and novel means involved in reducing their susceptibility to infection. Biol. Rev. 72:381-422.

6. Elad, Y., and Shtienberg, D. 1995. Botrytis cinerea in greenhouse vegetables: chemical, cultural, physiological and biological controls and their integration. Integr. Pest Manage. Rev. 1:15-29.

7. Elad, Y., Shtienberg, D., Yunis, H., and Mahrer, Y. 1992. Epidemiology of gray mold in vegetable greenhouses. Pages 272-276 in: Recent Advances in Botrytis Research. K. Verhoeff, N. E. Malathrakis, and B. Williamson, eds. Pudoc Scientific Publishers, Wageningen, the Netherlands.

8. Gamliel, A., Katan, T., Yunis, H., and Katan, J. 1996. Fusarium wilt and crown rot of sweet basil: involvement of soilborne and airborne inoculum. Phytopathology 86:56-62.

9. Garibaldi, A., Gullino, M. L., and Minuto, G. 1997. Diseases of basil and their management. Plant Dis. 81:124-132.

10. Hausbeck, M. K., and Pennypacker, S. P. 1991. Influence of time intervals among wounding, inoculation and incubation on stem blight of geranium caused by Botrytis cinerea. Plant Dis. 75:1168-1172.

11. Jarvis, W. R. 1980. Epidemiology. Pages 219250 in: The Biology of Botrytis. J. R. ColeySmith and W. R. Jarvis, eds. Academic Press, London.

12. Jarvis, W. R. 1989. Managing diseases in greenhouse crops. Plant Dis. 73:190-194.

13. Jarvis, W. R. 1992. Managing Disease in Greenhouse Crops. American Phytopathological Society Press, St. Paul, MN.

14. Lakshminarayana, S., Sommer, N. F., Polito, V., and Fortlage, R. J. 1987. Development of resistance to infection by Botrytis cinerea and Penicillium expansum in wounds of mature apple fruits. Phytopathology 77:1674-1678.

15. Nelson, K. E. 1951. Factors influencing the infection of table grapes by Botrytis cinerea. Phytopathology 41:319-326.

16. O'Neill, T. M., Shtienberg, D., and Elad, Y. 1997. Effect of some host and microclimate factors on infection of tomato stems by $\mathrm{Bo}$ trytis cinerea. Plant Dis. 81:36-40.

17. Sharabani, G., Shtienberg, D., Elad, Y., Dinoor, A., and Yunis, H. 1996. Development of gray mould in sweet basil. (Abstr.) Phytoparasitica 24:140.

18. Sharma, A., Tewari, R., and Virmani, O. P. 1987. French basil (Ocimum basilicum L.): A review. Curr. Res. Med. Aromat. Plants 9:136-151.

19. Shtienberg, D., and Elad, Y. 1997. Incorporation of weather forecasting to integrated, chemical-biological management of Botrytis cinerea. Phytopathology 87:332-340.

20. Yunis, H., Elad, Y., and Mahrer, Y. 1990. The effect of air temperature, relative humidity and canopy wetness on gray mold of cucumbers in unheated greenhouses. Phytoparasitica 18:203-215.

21. Yunis, H., Shtienberg, D., Elad, Y., and Mahrer, Y. 1994. Qualitative approach for modeling of outbreaks of gray mould epidemics in non-heated cucumber greenhouses. Crop Prot. 13:99-104. 